\title{
The Potential Impact of Incentives on Managed Lane Travel
}

\author{
Namoo A. Han', Mark W. Burris ${ }^{2}$ \\ ${ }^{1}$ Freese and Nichols, Dallas, TX, USA \\ ${ }^{2}$ Texas A\&M University, College Station, TX, USA \\ Email:Namoo.Han@Freese.com, mburris@tamu.edu
}

How to cite this paper: Han, N.A. and Burris, M.W. (2018) The Potential Impact of Incentives on Managed Lane Travel. Journal of Transportation Technologies, 8 , 255-272.

https://doi.org/10.4236/jtts.2018.84014

Received: July 12, 2018

Accepted: August 6, 2018

Published: August 9, 2018

Copyright ( 92018 by authors and Scientific Research Publishing Inc. This work is licensed under the Creative Commons Attribution International License (CC BY 4.0).

http://creativecommons.org/licenses/by/4.0/

(c) (i) Open Access

\begin{abstract}
The use of managed lanes to control and maximize freeway throughput is increasing. One way of encouraging more managed lane use is through the implementation of incentives. In the Dallas-Fort Worth area, a managed lane is being added to the I-30 (Tom Landry freeway) and incentives to maximize the use of this lane were planned. Since the managed lanes were not yet open and the incentives were hypothetical, a stated preference survey was used to gauge the potential impact of the incentives on traveler behavior. The stated preference questions were designed using $\mathrm{D}_{\mathrm{b}}$-efficient and random adaptive designs. The incentives were chosen by looking at other programs around the country and through discussion with transportation experts. Once ready, the survey was administered online to travelers in the area and a total of 898 usable responses were gathered. From the responses, a mixed-logit model was developed to describe and predict traveler behavior. From the model, elasticities were calculated to predict the impact of the incentives on mode choice. The model found that incentives with discounts and free trips (a transit fare discount, express bus service to downtown, a free trip for every $X$ number of paid trips, and a discount offered to select businesses) were more effective at encouraging managed lane use. The other incentives (gift card worth $\$ 5$ for every $X$ number of trips and $\$ 5$ in credit for every $X$ number of trips taken by transit) had less of an impact.
\end{abstract}

\section{Keywords}

Managed Lanes, Incentives, Stated Preference Survey

\section{Introduction}

One of the biggest challenges in transportation is traffic congestion on urban freeways. The growth of transportation infrastructure has not been able to keep 
pace with the increasing demand. One of the main reasons is the lack of funds to build new infrastructure. This has led to the increased use of managed lanes (MLs) to control and optimize freeway traffic. The definition of managed lanes can vary but the Federal Highway Administration (FHWA) defines them as "highway facilities or a set of lanes where operational strategies are proactively implemented and managed in response to changing conditions" [1]. MLs offer planners and officials a way to manage traffic on freeways through various methods including pricing, access control, and vehicle eligibility [1]. They offer travelers an alternate path that will be less congested, but for a price. Some facilities require vehicles to have multiple occupants and are known as high-occupancy vehicle (HOV) lanes. These lanes can be further differentiated by occupancy required, some simply require 2 or more occupants while others may require 3 or more. Other facilities may also allow single occupancy vehicles (SOV) on the managed lane but charge a toll. These facilities are known as high-occupancy/toll (HOT) lanes. Some facilities may have a fixed toll while others may adjust the price based on the time of day or level of congestion. This research focused on price MLs, such as HOT lanes.

The area of study for this research was the I-30 Freeway MLs in between Fort Worth and Dallas, also referred to as the Tom Landry Freeway (called the I-30 Express Lanes locally). Before expansion, the section was a six-lane divided freeway with one concurrent HOV lane for each direction. After construction, there will be 5 general purpose lanes per direction and additional managed lanes. The freeway section is notable for being a major route between Fort Worth and Dallas, serving the cities of Grand Prairie and Arlington, and also being near both the Dallas Cowboys and Texas Rangers' stadiums.

Estimating how the public will react to new managed lanes is a challenge, especially when the public is not familiar with them. When first opened, managed lanes can have a ramp-up period where traffic volume has not reached full potential [2]. Thus, incentives are being considered to encourage managed lane use in an effort to optimize the use of the entire freeway.

This research examines traveler's potential reaction to incentives for managed lane use through a stated preference survey. This research adds to the growing literature on estimating managed lane use which has traditionally focused on travel time savings. The research will help agencies examine how to optimize the use of their MLs.

\section{Research Problem}

The number of MLs is expected to increase in the coming years. Therefore, it is important to understand the best practices for implementing them. One method of encouraging managed lane use is through the use of incentives. Incentives have been used in the past to encourage carpooling or transit use, but rarely have they been used to encourage ML use. The I-30 MLs not only provide an opportunity to study how travelers rate incentives before the managed lanes are in- 
stalled, but also how they react to the incentives once the managed lanes are operational.

This research examined the potential impact of incentives on mode choice. This research tested six different incentives which could be offered for either using the managed lane by carpooling, paying the toll, or riding transit. Ultimately, this can help agencies operating MLs optimize the use of their MLs through offering carefully chosen incentives.

\section{Incentives Used in Practice}

In the world of transportation planning and management, incentives have generally been used to encourage modes of transportation or trip planning that have environmental or social benefits. Researchers have studied the effect of incentives in several different ways including surveys, pilot programs, and long term programs. For example, there have been programs that reward commuters for carpooling [3] [4] [5], using alternate modes of transportation [3], riding transit during peak hours [5], or driving during off-peak times [6]. Other programs have rewarded employers for having higher vehicle occupancy or allowing telecommuting.

If incentives are to be used, it is important to know which incentives would work best. Leblanc and Walker [7] used a stated preference survey of San Francisco travelers to examine potential impacts of incentives. In this survey, participants were offered hypothetical incentives to change their commutes. Participants could either leave at a different time, take a different route, or take a different travel mode. They tested various incentives including cash, entry to a prize drawing, and credit towards various rewards such as gift cards or coffee. They found that Apple store credit and cash were the most effective and also noted that travelers were more sensitive to charges than rewards.

Incentives have been offered for transit use to increase ridership or shift travel start time. One such survey was conducted by Zhang et al. in 2014 [8]. They surveyed commuters on the Beijing Subway System and offered incentives to avoid the rush hour period. They found that discounted fares and restaurant related incentives had the most potential for reducing morning rush congestion. Another study looked to determine which incentives would increase ridership the most. Bianco [9] assessed the effects of a plan to reduce single-occupancy vehicles by incentivizing transit use while also disincentivizing SOV use. This was done by offering discounted transit passes and by starting to charge for on-street parking. After a year, a survey of travelers in the area was conducted which found that SOV use decreased by $7 \%$.

Most research on incentives has focused on one transportation mode. However, this research will examine transportation behavior and mode choice with incentives on multiple modes.

\subsection{Pilot Programs}

Ettema et al. [10] offered cash or credits to earn a smartphone if the traveler 
avoided travelling in the peak period by car. Travelers generally responded by traveling alone but before or after the peak period. They observed that after the end of the program, many travelers did not sustain the change and returned to the peak period. Ben-Elia and Ettema in 2011 [11] used a 13-week pilot program to test how participants would adjust travel behavior if they were offered monetary or in-kind rewards for avoiding travel in the peak hour. To do this, the travelers could either change when they worked, switch travel modes, or telecommute. They found that in the short run, the monetary rewards and the Smartphone reward were especially effective in reducing rush-hour car commutes. Bliemer et al. in 2009 [12] examined three separate experiments conducted in the Netherlands and found that travelers were willing to change for monetary rewards. Both researchers expressed concern whether the change would be sustained after the end of the program. They also noted that mode choice is complex and dependent on many other factors such as location, education, attitudes, and information available.

\subsection{Long-Term Programs}

Cash for Commuters in Atlanta offered commuters $\$ 3$ for every day they used an alternative travel mode (bike, carpool, transit, vanpool, or walk) [3]. The Center for Transportation and Environment (CTE) conducted several surveys from 3 to 21 months after the participants had completed the program [13]. Around $70 \%$ of the participants continued to use the other modes after completion of the program. Another similar program, "Pool Reward\$”, in the DC metropolitan area encouraged vanpool and carpool usage by offering $\$ 1$ to new carpoolers every time they carpooled to work [4].

Other programs include the Dulles Greenway Cashback program, San Diego's iCommute prize drawing, and South Florida's 595 Express Bus. The Dulles Greenway Cashback program offers $5 \%$ to $15 \%$ cash back depending on how many trips were taken (with a minimum of 180 trips for a yearlong period) [14]. San Diego's iCommute program has a prize drawing every month for anyone who logged eight round-trip commutes by anything other than driving alone. The prize is separate for every mode of transportation and has a value of $\$ 100$ [15]. Several agencies offer express buses from park and ride lots to central business districts. One example is the 595 Express bus which offers a service to both downtown Fort Lauderdale and Miami [16].

Another program that encouraged alternative modes is the Metro Express Lanes on I-10 and I-110 in the LA area [5]. These managed lanes had a carpool loyalty program as well as a transit rewards program. The carpool program offers a monthly prize drawing where carpools (identified by their FasTrak transponder) are entered every time they carpool. $3+$ carpools are entered into a different drawing with larger prizes. Additionally, transit riders are also able to earn rewards by using transit during peak hours. For every 32 one-way trips taken, riders earned a $\$ 5$ toll credit that could be used on the Metro Express Lanes. This 
transit incentive program, which was touted as the first of its kind in the country, was implemented alongside tolling policy forcing the peak hour minimum toll to be no less than $150 \%$ of the Metro transit fare [17]. On average, 220 accounts enrolled in the program per month. On one of the transit lines, the Silver Line, ridership increased by $15 \%$ after the toll floor of $150 \%$ was put in place. A 2013 survey found that about a third of the new Silver Line riders were former commuters who drove alone on I-10 or I-110.

The area of this study, Dallas-Fort Worth, has also implemented programs to encourage other modes of travel. NCTCOG's main program is Try Parking It which rewards users for carpooling, biking, or other modes. It also offers a vanpool or carpool matching program to help travelers find partners.

Overseas, a large scale program was conducted by Merugu et al. in 2009 in Bangalore, India where they incentivized early commuting for employees of Infosys Technologies [6]. Employees were incentivized to avoid the peak and arrive earlier by offering entry into prize drawings. The program was able to roughly double the number of employees that arrived early.

This program was copied by Stanford University to reduce peak hour commutes by offering incentives to shift to non-peak hours or shift modes [18]. They offered rewards such as Rose Bowl tickets through raffles and were able to reduce inbound peak hour commutes by $22.8 \%$ and outbound peak hour commutes by $14.7 \%$. A survey was administered during the program asking if users shifted commute times. Out of the 1010 responses, 594 responded they did shift. However, many of those that did not shift were already traveling during the off-peak. The success, or lack thereof, of all of these incentive programs found in the literature helped shape what incentive programs were shown in our stated preference survey.

\section{Survey Development and Execution}

The I-30 Express Lanes Survey (note that these MLs are termed Express Lanes but have the same characteristics as MLs) was conducted from August 1, 2014 to November 30, 2014 with help from the North Central Texas Council of Governments and the Texas A\&M Transportation Institute. The survey had four sections of questions designed to obtain data from DFW travelers on their travel behavior and how potential incentives would affect their travel behavior. The first section gathered information on traveler's usual travel behavior on I-30 as well as their most recent trip on I-30. These questions included trip purpose, travel time, mode of transportation, and trip time of day. Most of these attributes (except trip distance-see stated preference question design) were then used for developing the stated preference questions (see Figure 1). Creating a hypothetical situation that is based on the respondent's actual trip can help result in more accurate responses [19]. The second section introduced managed lanes and the incentives that would be offered in the stated preference section. The third section consisted of three stated preference (SP) questions. The fourth 


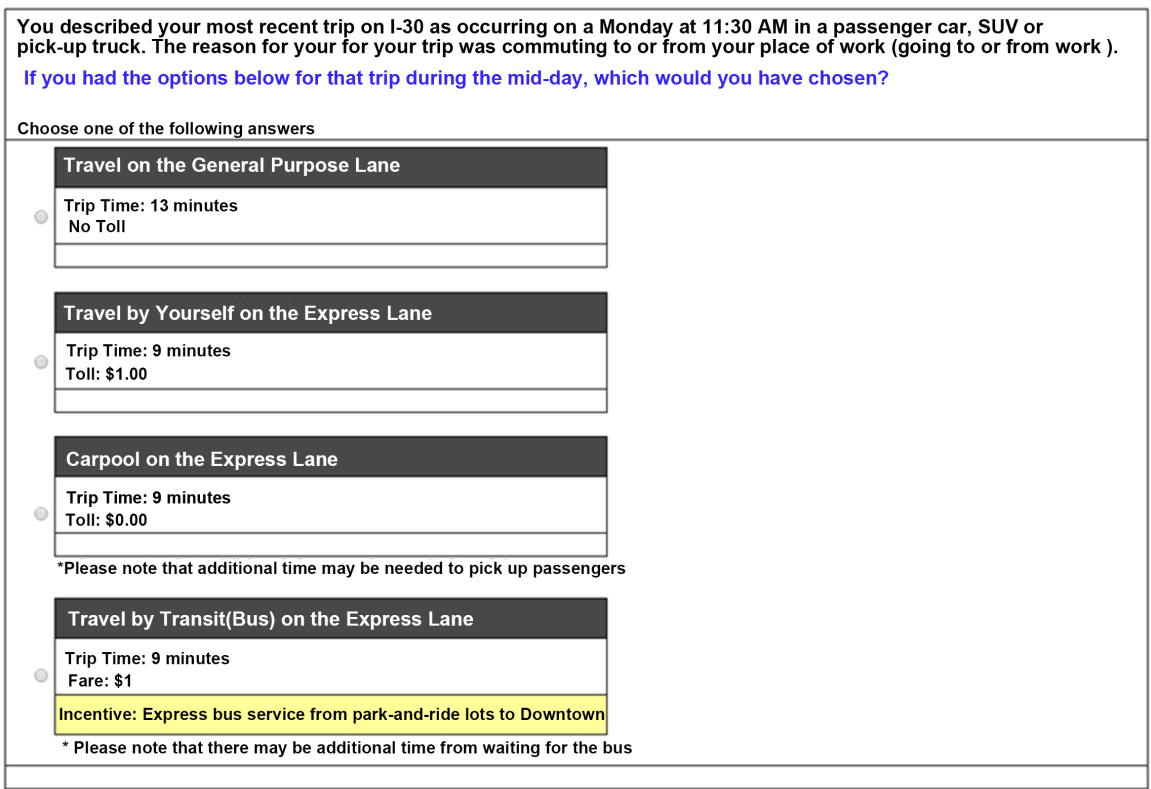

Figure 1. Typical SP question.

section consisted of questions to determine the respondent's socio-demographic characteristics, including gender, age group, level of education, and income. Some additional survey results, and a look at how they could be incorporated into ML policy is found in Wood, et al., 2017 [20]. This previous research did not go into an in-depth analysis of those SP responses, as outlined below.

\subsection{Stated Preference Questions}

Each SP question was a travel scenario on I-30 with the hypothetical managed lane and the respondents were given four options (alternatives) (see Figure 1):

1) Travel on the General Purpose Lane (GPL);

2) Travel by Yourself on the Express Lane, or Managed Lane Drive Alone (MLDA);

3) Carpool on the Express Lane, or Managed Lane Carpool (MLCP);

4) Travel on the Express Lane (Transit).

Each option was presented with two attributes, travel time and toll. GPL was always free, MLDA and Transit always had a toll or fare, respectively, and MLCP was either free or had a toll of half the MLDA toll. The travel time for MLDA, MLCP, and Transit were all the same since they all traveled on the Express Lane while the travel time for GPL was always longer. However, footnotes were included to indicate that carpooling may require extra time to pick up passengers and transit may require waiting time. The hypothetical situation was introduced in two different manners based on the responses given in the first section of the survey. If the respondent described their most recent trip, these characteristics would be used to build the hypothetical situation. If the respondent did not describe their most recent trip, the survey would develop a typical peak period travel scenario. Of the three stated preference questions, the first question did not have an incentive while the second and third included an incentive to use the 
MLs. The incentive was randomly chosen from the six different incentives and was highlighted by a different color background.

\subsection{Incentive Design}

The first step for choosing the incentives was to develop a list of any incentives that could be tested or implemented. This was done by both looking at previously offered incentives in the area, incentives offered by other programs around the country based on the literature review, and discussions with transportation experts. The list was then expanded by determining innovative ways that these existing ideas could be enhanced or combined. After creating a broad list of possible incentives, the next step was to narrow the list down through discussion and voting. The final incentives were chosen for both their potential impact on mode choice and practical potential for implementation. The final six incentives included (see Table 1):

1) For every 10 paid trips on the Express Lanes, you earn a free trip;

2) Gifts such as cash, gift cards, or gas cards to local retailers and entertainment venues if you telecommute or travel off peak in the Express Lanes;

3) Free items and discounts to local retailers and entertainment venues if you travel off peak in the Express Lanes;

4) Regular transit riders can earn credits towards reduced bus fares or reduced Express Lane tolls;

5) Reduced transit fares during peak hours;

6) An express bus service to downtown from park-and-ride lots on the Express Lanes (note that there is still a fare for this service-the incentive is that it would be a new service).

The focus of this research was to determine how travelers would be influenced by incentives for managed lane use and how their travel behavior would change. To do this, incentives were added to the managed lane travel modes for the second and third stated preference questions. The incentive added to the stated preference question was chosen randomly from the 6 to ensure each incentive was tested equally. Furthermore, because every incentive except one had a numerical aspect, those incentives were tested by randomly choosing the value from a set range (see levels in Table 1). If one of the first 3 incentives was randomly selected it was applied to all three Express Lane modes. If one of the last three incentives was randomly selected it was applied only to the transit mode.

Note that there were no explicit incentives for carpooling (the third travel option in the stated preference question). However, carpooling often received a significant discount on the toll or was not charged any toll (see toll rate section below). Therefore, carpooling was incentivized over and above to any of the above 3 Express Lane incentives offered.

\subsection{Stated Preference Question Design}

This section describes how the attribute levels (travel time and toll rate) were chosen and how the factors went into designing the stated preference scenarios. 
Table 1. Incentives used and their levels.

\begin{tabular}{lcc}
\hline \multicolumn{1}{c}{ Incentive } & Mode & Levels \\
\hline $\begin{array}{l}\text { 1) Earn a free trip for every } X \text { paid trips on the } \\
\text { Express Lanes }\end{array}$ & MLDA, MLCP & 8, 9, 10, 11, 12 \\
$\begin{array}{l}\text { 2) Earn gift cards worth } \$ 5 \text { for every } X \text { peak-hour } \\
\text { trips saved by either telecommuting or by not } \\
\text { traveling during the peak hours } \\
(7-9 \text { am or } 4 \text { - } 6 \text { pm) }\end{array}$ & MLDA, MLCP, Transit & $20,25,30,35$ \\
$\begin{array}{l}\text { 3) } X \% \text { discount offered through select businesses } \\
\text { 4) For every } X \text { trips taken by transit, } \$ 5 \text { in credits } \\
\text { that can be used on the Express Lanes }\end{array}$ & MLDA, MLCP, Transit & $5 \%, 10 \%, 15 \%, 20 \%$, \\
5) A transit fare discount of $X \%$ & Transit & $20 \%, 25,30,35$ \\
$\begin{array}{l}\text { 6) Express bus service from park-and-ride lots to } \\
\text { downtown }\end{array}$ & Transit & $10 \%, 20 \%, 30 \%$ \\
\hline
\end{tabular}

\subsubsection{Travel Time/Trip Time of Day Factor/Toll Rate}

Travel time is one of the most important factors a traveler considers when choosing among different modes or routes, so it was important to display a reasonable travel time in the stated preference question scenarios. Several factors went into calculating the travel time:

$$
T T=\frac{D * 60}{V / T D F}
$$

where: $T T=$ travel time (minutes);

$D=$ trip distance (miles);

$60=$ Constant to convert miles/hour to miles/minute;

$V=$ speed $(\mathrm{mph})$

$T D F=$ time of day factor.

The distance was set to 10 miles for every trip to provide a reasonable distance and one where the MLs would offer a meaningful travel time advantage over the GPLs. The speed used for the scenarios was based on data obtained from detectors on the freeway. The speeds used were $40 \mathrm{mph}$ to $60 \mathrm{mph}$ for the general purpose lane and $55 \mathrm{mph}$ to $75 \mathrm{mph}$ for the ML.

The time of day factor was dependent on the lane, GPL or ML, and the time period, morning shoulder, morning peak, mid-day, and so on. If the respondent provided the time their most recent trip started, that time period would be used. However, if the trip start time was not provided, the survey would default to either the am or pm peak time of day (randomly choosing between the two). The time of day factor ranged from 1 (off peak) to 1.8 (peak on GPLs) and were based on previous stated preference studies [21].

\subsubsection{Toll Rate and Transit Fare}

The second attribute of each travel mode was the cost-either the toll rate or transit fare. These were based on rates from existing managed lanes and transit in the area. The toll rate was taken from the existing LBJ TEX press Lanes, which is dynamically priced and dependent on the level of demand. The toll typically 
ranges from 10 - 25 cents per mile during the off-peak hours and 45 - 75 cents per mile during the peak hours [22]. Similarly, rates from the Dallas Area Rapid Transit were used to develop the fare range for transit use. As of 2015, the DART charged $\$ 2.50$ for a 2 hour pass that could be used on local lines, and $\$ 5.00$ for a 2 hour pass that could be used regionally. A local pass allowed riders to travel on all DART buses and trains while a regional pass allowed riders to also travel on all Fort Worth buses and transit. They also offered off-peak fares (9:30 am to $2: 30 \mathrm{pm}$ ) that cost $\$ 1.75$ for local trips and $\$ 3.50$ for regional trips [23]. With these fares and toll rates, a range was developed for the SP questions.

The toll range for the Express Lanes also depended on what travel mode was used. Driving alone on the Express Lane would always incur a toll which ranged from 30 to 50 cents per mile. The toll rate for carpooling was set to be free $50 \%$ of the time, and half the SOV toll rate the other $50 \%$ of the time. As for Transit, the trip was assumed to always be regional, and therefore the fare ranged from $\$ 3.50$ to $\$ 5.00$.

The first method used to generate the stated preference question's attributes was Bayesian $\mathrm{D}_{\mathrm{b}}$-efficient design. An efficient design estimates the attribute levels in a way that minimizes the standard error for the parameters and maximizes the t-statistic. The priors for travel time, toll rate, and transit fare were assumed to have normal distribution with a non-zero mean. The means for the priors were obtained from the results of a previous Transit to SOV study [24].

Because the calculation of the $\mathrm{D}_{\mathrm{b}}$-error is computationally difficult, $\mathrm{N}$-gene software was used to calculate the error and design the survey. Once the attribute levels and priors are inputted, a random parameter panel logit (rppanel) was specified for the discrete choice model and the priors were simulated using 400 Halton draws from the prior distribution. The result was 24 rows of questions divided into 8 blocks of 3 rows each. Every respondent would be given all three choice sets from a randomly chosen block. The $\mathrm{D}_{\mathrm{b}}$-error for this design was 0.74 . The smaller the $\mathrm{D}_{\mathrm{b}}$-error is, the more efficient the design is. The $\mathrm{D}_{\mathrm{b}}$-error is close to zero, which indicates an efficient design.

The other method used for generating the SP question attributes was Random Adaptive (RA). In this method, the attributes for the first SP question are randomly created from the same initial range as the D-efficient attribute levels. For travel time, this method was used for all three stated preference questions. The RA part is used in the calculation of toll and fare for SP questions 2 and 3.

For toll and fare, the attribute value was multiplied by a factor based on which mode the respondent chose in the previous question. If the general purpose lane was chosen in the previous question then the toll rate and transit fare were multiplied by a randomly generated factor between 0.35 and 0.7 . Thus the cost of the ML was lowered to see if that would entice a switch in preference from the respondent. Conversely, if the ML was chosen, the toll rate and fare was multiplied by a factor between 1.3 and 1.9. Thus, RA attempts to adjust the toll/fare such that it encourages more respondents to switch preference (ML or GPL) and thus may provide additional insight over SP questions where more respondents al- 
ways select the same choice. Note that constraints were included to ensure the toll would not be too high or too low.

\section{Analysis of Survey Results}

Once the data was all collected, there were a total of 1055 responses. The first step in analyzing the data was to check the responses to filter out unusable data. After filtering out both suspect responses and partial responses, we were left with 898 responses out of 1055 total. The responses from those who received the $\mathrm{SP}$ questions generated by the random adaptive and the $\mathrm{D}_{\mathrm{b}}$-efficient designs were compared. The responses were similar (see Han thesis [25]) and thus combined for the research presented here. Future efforts may include attempting to see if either design proved significantly better overall.

\subsection{Preliminary Analysis}

The first type of analysis done was an analysis of socio-demographic characteristics, the respondent's recent trip, and basic incentive statistics (see Table 2). A little over half of the respondents were male, and the majority (79\%) were White/Caucasian. The age was distributed fairly evenly while the income was skewed towards the higher end (over $30 \%$ earned over $\$ 100,000$ per year or more). These statistics were compared with socio-demographics of the Dallas-Fort Worth metropolitan area as well as the combined socio-demographics of Arlington and Grand Prairie. There were several numbers that differed between the survey and census data. The populations that were over represented included those who were white, college graduates, and those aged 55 - 64. Underrepresented groups included African Americans, Hispanic/Latino, those with less than high school or just a high school diploma, and those with an income less than $\$ 50,000$. The disparity is most likely due to the advertising targets as well as the online survey platform.

The data on the respondent's most recent trip is also shown in Table 2. The majority of travel was for work or social purposes. Virtually everyone who took the survey traveled by passenger vehicle, SUV, or pick-up truck at $99.2 \%$. The majority of respondents traveled alone (71.6\%). If the respondent did travel with someone else, it was usually a family member. Children were the passenger $17.5 \%$ of the time while adult family members were the passenger $55.3 \%$ of the time. Just over half of the respondents chose to utilize the same option for all three stated preference questions.

Most of the incentives had a range of values that could be offered. For example, for incentive 1: Earn a free trip for every [8] [9] [10] [11] [12] trips. This was done so that the value the traveler places on the incentives could be better explored.

\subsection{Model Development}

Modeling the mode choice allows for a more complete picture of the impacts of incentives. One of the advantages of modeling is that we can use it to determine 
Table 2. Recent trip characteristics.

\begin{tabular}{|c|c|}
\hline Trip Characteristic & Percentage of Travelers \\
\hline \multicolumn{2}{|l|}{ How Frequently do you travel on the I-30 (Tom Landry) Freeway? } \\
\hline Multiple times per day & 31.4 \\
\hline About once a day & 6.8 \\
\hline A few times per week & 22.5 \\
\hline Once a week & 7.3 \\
\hline A few times per month & 30.0 \\
\hline I have not used I-30 in the past 6 months & 2.3 \\
\hline \multicolumn{2}{|l|}{ What was the purpose of your most recent trip on I-30? } \\
\hline Commuting to or from work & 40.3 \\
\hline Recreational/Social/Shopping & 31.8 \\
\hline Major sports game & 2.5 \\
\hline Work related (non-commuting) & 15.4 \\
\hline Class or School & 4.0 \\
\hline Other & 6.1 \\
\hline \multicolumn{2}{|l|}{ On what day of the week was your most recent trip? } \\
\hline Sunday & 7.0 \\
\hline Monday & 14.8 \\
\hline Tuesday & 18.5 \\
\hline Wednesday & 12.0 \\
\hline Thursday & 16.2 \\
\hline Friday & 16.6 \\
\hline Saturday & 14.9 \\
\hline Average respondent trip time (minutes) & 31.8 \\
\hline Adjusted average respondent trip time ${ }^{\star}$ (minutes) & 29.6 \\
\hline$\%$ Passenger vehicle, SUV or Pick-up truck & 99.2 \\
\hline \multicolumn{2}{|l|}{ How many people were in the vehicle? } \\
\hline 1 & 71.6 \\
\hline 2 & 20.4 \\
\hline 3 & 5.3 \\
\hline 4 & 2.0 \\
\hline $5+$ & 0.7 \\
\hline Average occupancy & 1.40 \\
\hline \multicolumn{2}{|l|}{ Was the respondent the driver or passenger? } \\
\hline Driver & 73.1 \\
\hline Passenger & 26.9 \\
\hline Average time to pick up passenger (minutes) & 3.95 \\
\hline Adjusted average time to pick up passenger ${ }^{* *}$ (minutes) & 11.1 \\
\hline \multicolumn{2}{|l|}{ Passenger's relation to respondent } \\
\hline Neighbor & 2.9 \\
\hline Child & 17.5 \\
\hline Co-worker & 8.7 \\
\hline Adult family member & 55.3 \\
\hline Commuter in a casual carpool & 2.2 \\
\hline Other & 13.5 \\
\hline
\end{tabular}

*Adjusted by removing any travel times over 90 minutes; ${ }^{* *}$ Adjusted by removing all pick up times of 0 minutes. 
the impact of the incentives while controlling for variables that are more often used in mode choice analysis such as income level or toll.

\subsubsection{Model 1}

The base model consisted of travel time, toll, and the six incentives. However, before all the incentives could be used in the model, three of the values needed to be modified. This was because for three of the incentives (incentives 1,2, and 4 in Table 1), the incentive was better when the value was lower. Therefore, the inverse of the incentive was used in the model.

Many data were obtained in the survey on travelers and their trips. Therefore, the first step was to determine which variables were significant and could be useful for the model. This was done by creating multiple models to test the various variables. Variables that were significant at a 95\% level of confidence were kept. Furthermore, variables with a level of significance between $95 \%$ and $80 \%$ were further tested in a new model to determine if they would improve the model. The best model was based on the $\rho^{2}$ value, the percent of the mode choice correctly predicted, and the simplicity of the model. The final model developed and the variables chosen are shown in Table 3. Travel time and toll formed the base equation and were included as part of all four modes. Because the general purpose lane did not have any other variables, travel time and toll were its only variables. This first model forced the coefficients for the incentives to be the same for each mode. This helped to determine an overall elasticity of that incentive since there was a single $\beta$ value for each incentive.

\subsubsection{Model 2}

Next, model 2 was estimated that allowed the coefficients of the incentives to vary by mode. The $\mathrm{p}$-values and $\rho^{2}$ values were similar for the two models. Both models are shown in Table 3.

Although all the incentives were included in all the models, not all of them were statistically significant. Only incentive 1 (earn a free trip for every [8] [9] [10] [11] [12] paid trips), and incentive 5 (transit discount of [10\% - 30\%]) had p-values less than 0.1. However, it was necessary to include all the incentives in order to create a model where mode choice was influenced by each incentive. One of the stronger variables for predicting mode choice was the respondent's income. Respondents with a high income (greater than $\$ 100,000$ per year) were more likely to drive alone on the managed lane, respondents with a low income (less than $25 \mathrm{k}$ ) were more likely to carpool, and respondents with an income between $25 \mathrm{k}$ and $50 \mathrm{k}$ were more likely to utilize transit.

Incentive 2 (Earn gift cards worth $\$ 5$ for every [20]-[35] peak-hour trips saved by either telecommuting or by not traveling during the peak hours) and incentive 4 ( $\$ 5$ credit for every [20]-[35] trips taken by transit) had p-values that were much worse than the other incentives. Incentive 2 had a p-value of 0.88 and incentive 4 had a p-value of 0.83 . They also had negative coefficients implying that the incentive discouraged managed lane or transit use. Most likely, these incentives 
Table 3. Model parameters across surveys.

\begin{tabular}{|c|c|c|c|c|}
\hline Mode & Variable & Model 1 & Model 2 & Model 3 \\
\hline \multirow{2}{*}{ All Modes } & Travel time & $-0.11(0.00)$ & $-0.11(0.00)$ & $-0.10(0.00)$ \\
\hline & Toll & $-0.09(0.01)$ & $-0.09(0.23)$ & $-0.09(0.02)$ \\
\hline \multirow{8}{*}{$\begin{array}{c}\text { MLDA } \\
\text { (Managed Lane } \\
\text { Drive Alone) }\end{array}$} & ASC & $-2.34(0.00)$ & $-2.41(0.00)$ & $-2.37(0.00)$ \\
\hline & Trip purpose (sports) & $0.86(0.00)$ & $0.95(0.00)$ & $0.86(0.01)$ \\
\hline & Ethnicity (Hispanic) & $0.52(0.00)$ & $0.56(0.00)$ & $0.53(0.00)$ \\
\hline & High income $(>\$ 100,000)$ & $0.46(0.00)$ & $0.48(0.00)$ & $0.46(0.00)$ \\
\hline & Trip frequency (once a day) & $-1.17(0.00)$ & $-1.19 \quad(0.00)$ & $-1.16(0.00)$ \\
\hline & Inverse of incentive 1 & $3.01(0.05)$ & $4.3 \quad(0.01)$ & $0.30(0.06)$ \\
\hline & Inverse of incentive 2 & $-0.61(0.88)$ & $2.8(0.55)$ & $0.03(0.87)$ \\
\hline & Incentive 3 & $0.01(0.18)$ & $0.01(0.32)$ & $0.29(0.04)$ \\
\hline \multirow{9}{*}{$\begin{array}{c}\text { MLCP } \\
\text { (Managed Lane } \\
\text { Carpool) }\end{array}$} & ASC & $-4.02(0.00)$ & $-3.84(0.00)$ & $-4.05(0.00)$ \\
\hline & Trip purpose (commute) & $-0.70(0.00)$ & $-0.6(0.00)$ & $-0.70(0.00)$ \\
\hline & Ethnicity (Asian) & $1.46(0.00)$ & $1.45(0.00)$ & $1.46(0.00)$ \\
\hline & Ethnicity (Hispanic) & $0.52(0.00)$ & $0.56(0.00)$ & $0.53(0.00)$ \\
\hline & Low income $(<\$ 25,000)$ & $1.01(0.00)$ & $0.95(0.00)$ & $1.02(0.00)$ \\
\hline & Vehicle occupancy & $0.90(0.00)$ & $0.58(0.00)$ & $0.91(0.00)$ \\
\hline & Inverse of incentive 1 & $3.01(0.05)$ & $-2.32(0.48)$ & $0.30(0.06)$ \\
\hline & Inverse of incentive 2 & $-0.61(0.88)$ & $-4.33(0.34)$ & $0.03(0.87)$ \\
\hline & Incentive 3 & $0.01(0.18)$ & $0.01(0.34)$ & $0.29(0.04)$ \\
\hline \multirow{8}{*}{ Transit } & ASC & $-4.47(0.00)$ & $-4.5(0.00)$ & $-4.50(0.00)$ \\
\hline & $\begin{array}{l}\text { Low mid income } \\
(\$ 25,000 \text { to } \$ 50,000)\end{array}$ & $0.65(0.01)$ & $0.63(0.02)$ & $0.65(0.01)$ \\
\hline & Age $(18-24)$ & $0.68(0.08)$ & $0.69(0.07)$ & $0.68(0.08)$ \\
\hline & Age $(25-34)$ & $1.13(0.00)$ & $1.14(0.00)$ & $1.14(0.00)$ \\
\hline & Male & $0.58(0.01)$ & $0.59(0.01)$ & $0.58(0.01)$ \\
\hline & Inverse of incentive 4 & $-2.23(0.83)$ & $-2.33(0.82)$ & $0.03(0.94)$ \\
\hline & Incentive 5 & $0.02(0.08)$ & $0.02(0.08)$ & $0.49(0.11)$ \\
\hline & Incentive 6 & $0.30(0.37)$ & $0.3(0.37)$ & $0.31(0.36)$ \\
\hline \multicolumn{2}{|r|}{$\rho^{2}$} & 0.433 & 0.438 & 0.432 \\
\hline \multicolumn{2}{|r|}{ Adjusted $\rho^{2}$} & 0.426 & 0.430 & 0.426 \\
\hline \multicolumn{2}{|c|}{ Log likelihood function } & -2001 & -1983 & -2001 \\
\hline \multicolumn{2}{|c|}{ Number of observations } & 2544 & 2544 & 2544 \\
\hline \multicolumn{2}{|r|}{ Chi-squared } & 437 & 475 & 438 \\
\hline \multicolumn{2}{|c|}{ Value of travel time savings } & $\$ 70.42 / \mathrm{hr}$ & $\$ 76.01 / \mathrm{hr}$ & $\$ 73.47 / \mathrm{hr}$ \\
\hline
\end{tabular}

p-values in parenthesis.

had little effect on mode choice and the travelers chose the mode due to other reasons such as travel time savings.

\subsubsection{Model 3}

A third model (see Table 3) was also created that did not take into account the 
value of the incentive. Instead, a dummy variable was used for each incentive (offered/not offered). Because the value of the incentive did not seem to have a significant effect, this model had the potential to better predict mode choice. All the other variables were kept the same as with model 1.

The incentives for driving alone or carpooling on the managed lane were more significant in this second model. The p-value for incentive 3 (5\% - 25\% discount to local retailers) improved from 0.18 to 0.04 . The change in p-value for transit incentives weren't as successful. In fact, the two p-values increased slightly. However, the coefficient for incentive 4 (\$5 credit for every [20]-[35] trips taken by transit) changed from -2.23 to 0.03 . This is a positive change for the model, but has little meaning since the p-values are far too large to indicate the variable has any significant impact on the model.

The models were also used to calculate a value of travel time savings. The values obtained from all three models were just over $\$ 70.42 /$ hour. Although this value is higher than those reported in most literature, it is not uncommon for the VTTS on managed lanes to be higher than most scenarios. Typical values of time on freeways are around $\$ 20 /$ hour while values of time on managed lanes can easily be as high as $\$ 51 /$ hour (24).

\subsection{Elasticities}

The models were then used to develop elasticities of the incentives. Elasticities are useful for predicting how utilities and mode choice will change if the incentive values are adjusted. This is especially useful for the I-30 managed lanes since some managed lanes operate by adjusting values to reach desired speeds.

The elasticities shown in Table 4 were calculated using the survey data and model 1. For example, the number of respondents selecting transit might be first estimated by the model assuming a value of incentive 5 (reduced transit fares during peak hours). The value of incentive 5 would then be changed and the new number of respondents choosing transit would be estimated. The elasticity (using the shrinkage ration formula of percent change in demand divided by percent change in incentive) was then calculated for this change in incentive 5 . Next, every elasticity possible for every change in incentive 5 was estimated in the same manner. All of these elasticities were averaged to produce the result found in Table 4. Elasticity calculation details can be found in Han, N. (2015) thesis [25].

The incentive results of the modeling and elasticity calculations can be seen in Table 4. In this table, the incentives are ranked in order of greatest to least elasticity. Incentive 6 (express bus service to downtown) has a two outcomes-it exists or does not exist-and thus does not have an elasticity. It was ranked based on its percent change in use from model 2. Noticeably, the two incentives that required 20 - 35 trips to earn the reward were the only two incentives with negative elasticity. This is not especially surprising since the value obtained ( $\$ 5$ dollar gift card or $\$ 5$ in credits) is fairly low compared to the required number of trips. 
Table 4. Incentives ranked by elasticity.

\begin{tabular}{clc}
\hline Rank & \multicolumn{1}{c}{$\begin{array}{c}\text { Incentive } \\
\text { Description }\end{array}$} & $\begin{array}{c}\text { Elasticity or \%Change } \\
\text { (with respect to } \\
\text { MLCP or Transit) }\end{array}$ \\
\hline $\mathbf{1}$ & (INC 5) A transit fare discount of [10\% - 30\%] & 0.366 (transit) \\
$\mathbf{2}$ & $\begin{array}{l}\text { (INC 6) Express bus service from park-and-ride lots to downtown } \\
\mathbf{3}\end{array} \quad \begin{array}{l}\text { (INC 1) Earn a free trip for every [8] [9] [10] [11] [12] paid trips } \\
\text { on the Express Lanes }\end{array}$ & $33.1 \%$ (transit) \\
$\mathbf{4}$ & $\begin{array}{l}\text { (INC 3) [5\% - 25\%] discount offered through select businesses } \\
\text { (INC 2) Earn gift cards worth \$5 for every [20]-[35] peak-hour }\end{array}$ & 0.254 (MLCP) \\
$\mathbf{5}$ & $\begin{array}{l}\text { trips saved by either telecommuting or by not traveling during the } \\
\text { peak hours (7 - 9 am or 4 - 6 pm) }\end{array}$ & -0.019 (MLCP) \\
$\mathbf{6}$ & $\begin{array}{l}\text { (INC 4) For every [20]-[35] trips taken by transit, \$5 in credits that } \\
\text { can be used on the Express Lanes }\end{array}$ & -0.073 (transit) \\
\hline
\end{tabular}

Overall, most of the incentives had a potential impact on the mode choice and it is important to note that the results from this survey do not mean that some incentives should not be considered. In other cities or with adjustments to the incentive, they could become more effective. Also, while the elasticities may seem small, leading to modest volume changes, the effects can still help tweak demand to maximize managed lane use.

\section{Conclusions}

Overall, travelers were generally set in their specific mode choice (usually driving alone). Still, the incentives made an impact in the models and any bit of change can help maximize managed lane use. Some incentives such as incentive 3 ([5\% - 25\%] discount offered through select businesses) were relatively successful (higher elasticities), indicating that the incentives would influence some travelers. Other incentives such as incentive 2 (Earn gift cards to local retailers worth $\$ 5$ for every [20]-[35] trips) were less impactful. However, this doesn't necessarily mean that those incentives will not work. Incentives put into practice may have a better impact, especially if the value of the incentive is increased. Regardless, past experience has shown that the incentives must be broadly advertised and very easy to use for travelers to take advantage of them, especially if that involves changing their travel behavior.

Although this research was able to provide some insight into the use of incentives on managed lane travel, there were several limitations that affected the study. One of the biggest limitations was the hypothetical nature of the research as several aspects of the survey were not easy for some respondents to relate to. For example, a major focus of the survey was to gauge interest in transit incentives. However, many travelers in the DFW area don't have access to transit. The electronic nature of the survey and advertisements may have also affected the demographics of the respondents. Because the survey was online and most of the advertisements were through the internet, lower income travelers without internet access may be been underrepresented by the results. 
Suggested future research would help provide more insight into the impact of incentives. This includes comparing how much impact the actual incentives on I-30 (still in the planning stage as of the writing of this paper) to the stated preference survey results. With that information, it would be possible to estimate the benefits and costs of each incentive.

\section{Highlights}

- Managed lanes opening on the I-30 Freeway in Dallas.

- Stated Preference Survey administered to potential users of these new managed lanes.

- Examined the potential impact of various incentives on managed lane use.

- Discounts at select businesses were relatively successful.

- Earning gift cards worth \$5 for every [20]-[35] trips was less impactful.

\section{Acknowledgements}

The contents of this paper reflect the views of the authors, who are responsible for the facts and the accuracy of the data presented herein. This paper was a result of research conducted in cooperation with the Federal Highway Administration (FHWA) through its Value Pricing Pilot Program and the North Central Texas Council of Governments (NCTCOG). The authors gratefully acknowledge the contributions of numerous individuals and organizations who made the successful completion of this paper possible, particularly project managers Natalie Bettger and Dan Lamers from NCTCOG. The authors also thank all the Texas A\&M Transportation Institute staff that helped to conduct the surveys and collect the data.

\section{Conflicts of Interest}

The authors declare no conflicts of interest regarding the publication of this paper.

\section{References}

[1] Federal Highway Administration (FHWA) (2013) Managed Lanes: A Primer. http://ops.fhwa.dot.gov/publications/managelanes_primer/

[2] Goodin, G., Benz, R., Burris, M., Brewer, M., Wood, N. and Geiselbrecht, T. (2013) Katy Freeway: An Evaluation of a Second-Generation Managed Lanes Project (No. FHWA/TX-13/0-6688-1).

[3] Clean Air Campaign (2009) Commuter Rewards: Cash for Commuters. https://georgia.gov/blog/2012-08-29/clean-air-campaign-commuter-rewards

[4] Commuter Connections. Poll Rewards for Carpools. http://www.commuterconnections.org/commuters/ridesharing/pool-rewar ds/pool-rewards-carpools/

[5] Metro ExpressLanes (2014) How It Works. https://www.metroexpresslanes.net/en/about/howit.shtml

[6] Merugu, D., Prabhakar, B.S. and Rama, N. (2009) An Incentive Mechanism for Decongesting the Roads: A Pilot Program in Bangalore. Proceedings of ACM NetEcon 
Workshop, Standford, July 2009.

[7] Leblanc, R. and Walker, J. L. (2013) Which Is the Biggest Carrot? Comparing Nontraditional Incentives for Demand Management. Transportation Research Board 92nd Annual Meeting, Washington DC, 13-17 January 2013.

[8] Zhang, Z., Fujii, H. and Managi, S. (2014) How Does Commuting Behavior Change Due to Incentives? An Empirical Study of the Beijing Subway System. Transportation Research Part F: Traffic Psychology and Behaviour, 24, 17-26. https://doi.org/10.1016/j.trf.2014.02.009

[9] Bianco, M. (2000) Effective Transportation Demand Management: Combining Parking Pricing, Transit Incentives, and Transportation Management in a Commercial District of Portland, Oregon. Transportation Research Record: Journal of the Transportation Research Board, 1711, 46-54.

[10] Ettema, D., Knockaert, J. and Verhoef, E. (2010) Using Incentives as Traffic Management Tool: Empirical Results of the "Peak Avoidance" Experiment. Transportation Letters, 2, 39-51. https://doi.org/10.3328/TL.2010.02.01.39-51

[11] Ben-Elia, E. and Ettema, D. (2011) Rewarding Rush-Hour Avoidance: A Study of Commuters' Travel Behavior. Transportation Research Part A: Policy and Practice, 45, 567-582. https://doi.org/10.1016/j.tra.2011.03.003

[12] Bliemer, M.C., Dicke-Ogenia, M. and Ettema, D. (2009) Rewarding for Avoiding the Peak Period: A Synthesis of Three Studies in The Netherlands. 12th International Conference on Travel Behavior Research, Jaipur, 13-18 December 2009.

[13] Georgia Department of Transportation (2009) Cash for Commuters: Survey Key Findings.

http://www.dot.ga.gov/DriveSmart/Travel/Documents/AirQuality/reports/2009-Cas hforCommutersSurvey.pdf

[14] Dulles Greenway (2014) VIP Program Overview. http://www.dullesgreenway.com/vip-program

[15] iCommute. Prize List. http://www.icommutesd.com/docs/default-source/prize/icommute-monthly-prizes. pdf?sfvrsn=16

[16] Florida Department of Transportation. 595 Express Bus Overview. http://595express.info/expressbus.shtm

[17] Higueros, E. (2014) Metro ExpressLanes, Transit Rewards Program.

[18] Prabhakar, B. (2014) Active Demand Management (Part 1). Active Transportation and Demand Management Webinar Series. https://www.nhi.fhwa.dot.gov/resources/docs/active_demand_mgmt_part1.pdf

[19] Rose, J.M., Bliemer, M.C., Hensher, D.A. and Collins, A.T. (2008) Designing Efficient Stated Choice Experiments in the Presence of Reference Alternatives. Transportation Research Part B: Methodological, 42, 395-406. https://doi.org/10.1016/j.trb.2007.09.002

[20] Wood, N., Burris, M., Geiselbrecht, T., Bettger, N. and Lamers, D. (2017) Application of Traffic Thermostat for the I-30 Managed Lanes in Dallas, Texas. Journal of the Transportation Research Board, 2616, 104-113. https://doi.org/10.3141/2616-11

[21] Harline, C. (2013) The Impact of Traffic Images on Mode Choice in Stated-Preference Surveys. Thesis, Texas A\&M University, College Station.

[22] LBJ TEXpress. How Pricing Is Determined. http://www.lbjtexpress.com/pricing/how-pricing-is-determined 
[23] DART Fares. https://www.dart.org/fares/fares.asp

[24] Chum, G. and Burris, M. (2008) Potential Mode Shift from Transit to Single-Occupancy Vehicles on a High-Occupancy Toll Lane. Transportation Research Record: Journal of the Transportation Research Board, 2072, 10-19. https://doi.org/10.3141/2072-02

[25] Han, N. (2015) The Impact of Incentives on Managed Lane Travel. Thesis, Texas A\&M University, College Station. 